PROFESSIONAL ISSUES

\title{
Circle of Security parenting program efficacy for improving parental self-efficacy in a South African setting: Preliminary evidence
}

\author{
Jenny Rose ${ }^{*, 1}$, Nicolette Roman $^{2}$ (iD) and Kelvin Mwaba ${ }^{1}$ \\ ${ }^{1}$ Department of Psychology, University of the Western Cape, Cape Town, South Africa \\ ${ }^{2}$ Department of Child and Family Studies, University of the Western Cape, Cape Town, South Africa \\ *Corresponding author email: jrose@uwc.ac.za
}

\begin{abstract}
This pilot study examined the cross-cultural transportability of a western Circle of Security (COS) parenting program to improve on levels of parental self-efficacy in a South African setting. Participants $(n=9)$ were sampled from a fishing community on the West Coast of South Africa. The participants completed the COS with pre-test and post-test measures of their parenting self-efficacy. Furthermore, they completed an open-ended measure of their satisfaction with the parenting program. The data were analysed using the Wilcoxon sign-rank test and the Sign test to determine the significance in differences between pre-to-post-test change scores. In addition, a thematic analysis was conducted on participant's satisfaction with the parenting program. Results indicated significant and possible change scores for the efficacy scores: ability to handle parenting pressures, control, and learning. The participants considered the COS program appropriate to their context and situation. These preliminary findings support the need for further study of the COS parenting program within the broader context of South Africa.
\end{abstract}

Keywords: attachment, circle of security parenting program, feasibility, parental self-efficacy, parenting program, self-efficacy

\begin{abstract}
Introduction
Successful parenting demands efficacy in child-care roles and related "tasks and responsibilities" (Whittaker \& Cowley, 2006, p. 297). Various researchers (Coleman \& Karraker, 2003; Jones \& Prinz, 2005; Teti \& Gelfand, 1991) have identified parenting self-efficacy as a key determinant of parenting behaviours, being closely linked to psychosocial child adjustment and child development outcomes. Parenting self-efficacy is a trainable skill (Wittkowski, Dowling, \& Smith, 2016). However, few parenting programs implemented in South Africa have explored this aspect. One study conducted in South Africa found that levels of self-efficacy in discipline and teaching roles were the lowest (Harty, Alant, \& Uys, 2006) and parents with a high self-efficacy may be better at childcare tasks, although this may vary by domain.
\end{abstract}

\section{Circle of Security parenting program}

The Circle of Security (COS) parenting program (Cooper, Hoffman, Marvin, \& Powell, 2000) is an American program with a focus on parent self-perceptions in the parenting roles important for a quality parent-child relationships (see Table 1). It is focused on the attachment relationship and enhances secure attachment between a parent and his/her child (Powell, Cooper, Hoffman, \& Marvin, 2009).

Each chapter was presented to participants, using both a manual and DVD with videos and scenarios providing examples to parents. Participants received hand-outs that they were able to refer back to. The hand-outs included activities for the parents to engage with. Furthermore, each chapter included sections that facilitated interaction and discussions amongst the group, with an opportunity for participants to ask questions about the content of the chapter. Additionally, there were designated places to stop and engage parents in reflective dialogue regarding the program content. A series of reflective questions were suggested in the manual in order to facilitate and guide the discussion. Pre-testing was done on the beginning of the first day, and post-testing and focus group discussions were run on the final day, at the end of the parenting program.

The various chapters across the three days corresponded to different domains relating to parental self-efficacy. During the three days, parents were mostly exposed to the following domains: emotion, empathy, selfacceptance, control, and learning. .

The COS program aims to encourage parents to reflect on their family structures and through introspection, their own attachment patterns as well. The specific questions that guided the program were as follows:

- What are the levels of parental self-efficacy prior to the intervention?

- What are the levels of parental self-efficacy following the intervention?

- Is the intervention accessible to parents in a low resource, low-income community?

\section{Method}

\section{Research design}

The study used a pre-test-post-test design to study changes in parental efficacy beliefs over the three day intervention period. The pre-test was administered at the start of the first day, while the post-test was administered at the end of the third day. Parents completed a parenting self-efficacy measure at the beginning of the intervention and at the end of the intervention. At the end of the program trial, 
Table 1. COS schedule

\begin{tabular}{|c|c|c|c|}
\hline Chapter / Content & Day & $\begin{array}{l}\text { Goal (linked to all chapters and are } \\
\text { across the program) }\end{array}$ & Parental self-efficacy domain \\
\hline $\begin{array}{l}\text { Chapter 1: Welcome to the Circle of } \\
\text { Security Parenting }\end{array}$ & Day One & $\begin{array}{l}\text { Increase security of attachment of the } \\
\text { child to the parent }\end{array}$ & Emotion and Empathy \\
\hline $\begin{array}{l}\text { Chapter } 2 \text { Exploring our children's needs } \\
\text { all the way around the circle }\end{array}$ & Day One & $\begin{array}{l}\text { Increase parent's ability to read the } \\
\text { child's cues }\end{array}$ & Empathy and Learning \\
\hline Chapter 3: 'Being With' on the circle & Day Two & $\begin{array}{l}\text { Increase empathy in the parent for } \\
\text { the child }\end{array}$ & Empathy and Learning \\
\hline $\begin{array}{l}\text { Chapter 4: 'Being With' with infants on } \\
\text { the circle }\end{array}$ & Not covered & $\begin{array}{l}\text { Decrease negative attributions of } \\
\text { the parent regarding the child's } \\
\text { motivations }\end{array}$ & Pressures and Learning \\
\hline Chapter 5: The path to security & Day Two & $\begin{array}{l}\text { Increase parents capacity to } \\
\text { self-reflect }\end{array}$ & Self-acceptance, Learning, Emotion \\
\hline Chapter 6: Exploring our struggles & Day Two & $\begin{array}{l}\text { Increase parent's capacity to pause, } \\
\text { reflect, and chose security-promoting } \\
\text { caregiving behaviours }\end{array}$ & Emotion, Learning, Control \\
\hline $\begin{array}{l}\text { Chapter 7: Rupture and repair in the } \\
\text { relationship }\end{array}$ & Day Three & $\begin{array}{l}\text { Increased parent's capacity to } \\
\text { regulate stressful emotional states, } \\
\text { and provide comfort when child is in } \\
\text { distress }\end{array}$ & Control, Discipline, Pressures \\
\hline Chapter 8: Summary and conclusion & Day Three & $\begin{array}{l}\text { Increase parent's ability to recognise } \\
\text { ruptures in the relationship and } \\
\text { facilitate repairs }\end{array}$ & Emotion, Self-acceptance \\
\hline
\end{tabular}

participants completed a focus group discussion on their experience with the program covering aspects of what they found useful to them, and aspects that did not seem beneficial.

\section{Participants and setting}

Participants $(n=9)$ included parents of children who attended a crèche in a rural fishing community along the West Coast of South Africa. Of the parents that participated, five (56\%) were female and four (44\%) were male; eight $(89 \%)$ participants were mixed-race (coloured), while one participant was Caucasian (11\%). The participants were between the ages of 28 and 51 .

\section{Procedure and instruments}

The University of the Western Cape's Higher Degrees Committee and Senate Higher Degrees Committee provided ethics approval for the study (Ref. 14/6/22). Participants consented to participate in the study.

The participants completed the Tool to Measure Parenting Self-Efficacy (TOPSE: Kendall \& Bloomfield, $2005)$ both pre- and post-test. The TOPSE consists of 48 items and 8 sub-scales, namely: emotion, play, empathy, control, discipline, pressures, self-acceptance, and learning. Items are scored on an 11-point Likert scale from 0 (strongly disagree) to 10 (strongly agree). Scores from the TOPSE achieved reliability indices of between 0.80 and 0.94 in a previous study (Kendall \& Bloomfield, 2005).

For the focus group discussion, the participants responded to questions regarding the parenting interventions. In particular, areas covered related to the accessibility of the program, considering aspects such as language, cultural relevance, hand-outs, and the use of audio-visual aids. Participants were asked to reflect on the usefulness of the program, the extent to which they were able to identify with the scenarios provided, the extent to which they were able to apply what they had learned to their own circumstances, and the applicability of the intervention within a diverse context.

\section{Data analysis}

Pre- and post-tests change scores were tested for significance utilising the Wilcoxon sign-rank test and Sign test. Thematic analysis of the data from the focus group discussion was primarily descriptive of the participants' satisfaction with and experience of the COS program.

\section{Results and discussion}

Tables 2 and 3 present the descriptive statistics for the nine parenting self-efficacy variable pairs. As can be observed from Tables 2 and 3, all variable pairs increased from preto post-test, except for the item on self-acceptance.

Table 4 indicates the results of the Wilcoxon SignRank test on eight of the nine variable pairs (for Pre and Post Play, the Sign test is used instead). As evidenced in Table 4, change scores were significant for: Control, $Z=-2.073, p<0.05$; Pressures, $Z=-1.965, p<0.05$; Learning, $Z=-2.521, p<0.05$; and the TOPSE Total, $Z=-2.429, p<0.05)$.

Moreover, the results of the Sign Test indicate that there was no significant change scores for the Play subscale. When considering the various domains of parental self-efficacy, tapped into during the three days, it seems that the domains that took precedence were those that linked to aspects of attachment and understanding of the parent's role as a safe haven and as a secure base. Consequently, the domain least efficacious during the program training was that related to play, as evidenced by no difference in scores post intervention. This could result from a lack of focused time on this domain. However, it could also speak to a wider issue relating to the subject of play within the parent-child relationship. Parents are often overwhelmed by the physical and financial demands 
Table 2. Descriptive statistics for TOPSE pre-test scores $(N=9)$

\begin{tabular}{lcccc}
\hline Pre-test & $M$ & SD & Min. & Max. \\
\hline Emotion & & & 32 & 59 \\
Play & 50.38 & 7.93 & 15 & 60 \\
Empathy & 47.62 & 13.41 & 33 & 60 \\
Control & 48.85 & 7.19 & 9 & 56 \\
Discipline & 36.46 & 12.25 & 20 & 50 \\
Pressures & 38.69 & 10.33 & 11 & 54 \\
Self-acceptance & 35.00 & 12.21 & 23 & 59 \\
Learning & 45.62 & 6.85 & 33 & 59 \\
TOPSE Total & 48.38 & 8.00 & 26.64 & 55.25 \\
\hline
\end{tabular}

Table 3. Descriptive statistics for TOPSE post-test scores $(N=9)$

\begin{tabular}{lcccc}
\hline Post-test & $M$ & SD & Min. & Max. \\
Emotion & 53.22 & 6.12 & 41 & 59 \\
\hline Play & 51.56 & 9.15 & 30 & 60 \\
Empathy & 51.78 & 6.08 & 38 & 59 \\
Control & 42.67 & 6.54 & 30 & 51 \\
Discipline & 45.89 & 11.04 & 30 & 60 \\
Pressures & 39.67 & 12.30 & 20 & 55 \\
Self-acceptance & 47.44 & 7.60 & 38 & 60 \\
Learning & 54.33 & 3.35 & 49 & 60 \\
TOPSE Total & 48.31 & 5.265 & 39.38 & 54.88 \\
\hline
\end{tabular}

Table 4. Wilcoxon sign-rank test statistics

\begin{tabular}{|c|c|c|c|c|c|c|c|c|c|}
\hline & 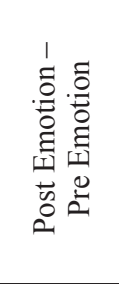 & $\begin{array}{l}\frac{\vec{\pi}}{2} \\
0 \\
0 \\
1 \\
1 \\
\frac{\vec{a}}{2} \\
\frac{1}{0} \\
0 \\
0\end{array}$ & 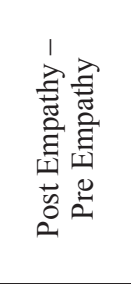 & 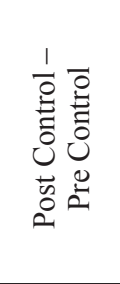 & 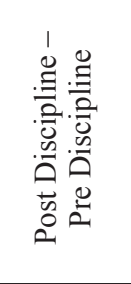 & 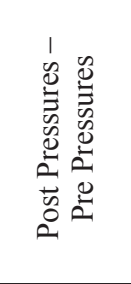 & 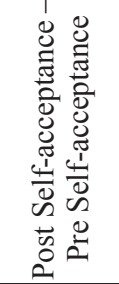 & 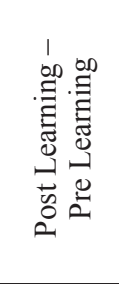 & 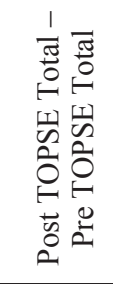 \\
\hline $\bar{Z}$ & $-1.630 b$ & $-1.192 b$ & $-1.472 b$ & $-2.073 b$ & $-1.838 b$ & $-1.965 b$ & $-1.362 b$ & $-2.521 b$ & $-2.429 b$ \\
\hline Sig. & 0.103 & 0.233 & 0.141 & 0.038 & 0.066 & 0.049 & 0.173 & 0.012 & 0.015 \\
\hline
\end{tabular}

Note. $\mathrm{b}=$ based on negative ranks.

of parenting, that often the emotional demands become secondary. Beyond this, an aspect like play is placed at the bottom of the list of priorities, as there seems to be so many other components that take overwhelming precedence. For reasons not apparent, some appear to lack in child play skills or awareness of the importance of play with their child.

Furthermore, many of the parents voiced that they often become parents quite suddenly, often unprepared and unplanned, with a verbalised notion of not knowing what should be done and a general state of feeling overwhelmed. Subsequently, unplanned parenting might harm parenting self-efficacy (Atkinson, Paglia, Coolbear, Niccols, Parker, \& Guger, 2000; Campbell, Brownell, Hungerford, Speiker, Mohan, \& Blessing, 2004; Martins \& Gafan, 2000). In communities with high poverty rates, parents tend to be at an elevated risk for maternal depression (Patel, Rodrigues, \& DeSouza, 2002), which may negatively impact on their parenting self-efficacy. For example, research in a rural settlement in Cape Town, showed marked impairments in mother-child interactions as a result of maternal postpartum depression (Cooper, Tomlinson, Swartz, Woolgar, Murray, \& Molteno, 1999).

\section{Subjective experience of the COS program}

Participants reported satisfaction with the program and its utility in enhancing their understanding of their parental role. For example, they made the following observations:

... it was a very good program ....It's practical and you remember it more. (Participant \#3, 51 years of age, female)

... [use] of the DVD ...makes it much easier and understandable. (Participant \#2, 38 years of age, male)

I realised I still have a lot to learn as a parent. (Participant \#8, 29 years of age, male)

I would recommend it to other parents... specifically if I hear or see a parent struggling with the relationship between him or her and her children. (Participant \#6, 31 years of age, female) 
The program utilises conversational style language which is accessible to ordinary parents. For instance, each aspect speaks to different parts of the parent-child relationship, with parents learning to apply each aspect to their own scenarios.

\section{Limitations of the study and suggestions for further research}

As this was a feasibility study, greater focus was ascribed to the accessibility of the program. This, in conjunction with the need from the community for a short and impactful intervention, that was presented in a way that promoted attendance, resulted in a shorter version of the parenting program being offered. Therefore, significant limitations of this study include the small sample size and short duration of the parenting program than is proposed in the original manual. For these reasons, the results of this study need to be interpreted with caution. Nonetheless, the preliminary evidence for the COS parenting program is encouraging and worthy of further study in similar developing contexts.

\section{Conclusion}

The COS parenting program showed positive outcomes relating to parental self-efficacy. This preliminary study gives preliminary evidence of the efficacy of this Western developed attachment-based program in the South African context.

\section{ORCID}

Nicolette Roman http://orcid.org/0000-0002-4506-437X

\section{References}

Andrews, D., \& Dowden, C. (2005). Managing correctional treatment for reduced recidivism: A meta-analytic review of programme integrity. Legal and Criminological Psychology, 10(2), 173-187. https://doi.org/10.1348/135532505X36723

Atkinson, L., Paglia, A., Coolbear, J., Niccols, A., Parker, K. C., \& Guger, S. (2000). Attachment security: A meta-analysis of maternal mental health correlates. Clinical Psychologist, 20(8), 1019-1040. https://doi.org/10.1016/ S0272-7358(99)00023-9 PMID:11098398

Blome, W., Bennett, S., \& Page, T. (2010). Organizational challenges to implementing attachment-based practices in public child welfare agencies: An example using the Circle of Security ${ }^{\circledR}$ Model. Journal of Public Child Welfare, 4(4), 427-449. https://doi.org/10.1080/15548732.2010.526904

Bloomfield, L., \& Kendall, S. (2012). Parenting self-efficacy, parenting stress and child behaviour before and after a parenting programme. Primary Health Care Research and Development, 13(4), 364-372. https://doi.org/10.1017/ S1463423612000060 PMID:22464178

Campbell, S. B., Brownell, C. A., Hungerford, A., Spieker, S. I., Mohan, R., \& Blessing, J. S. (2004). The course of maternal depressive symptoms and maternal sensitivity as predictors of attachment security at 36 months. Journal of Developmental Psychology, 16(2), 231-252. https://doi. org/10.1017/S0954579404044499 PMID:15487594
Cooper, P. J., Tomlinson, M., Swartz, L., Woolgar, M., Murray, L., \& Molteno, C. (1999). Post-partum depression and the mother-infant relationship in a South African peri-urban settlement. Journal of Psychiatry., 175(06), 554-558. https:// doi.org/10.1192/bjp.175.6.554 PMID:10789353

Deković, M., Asscher, J. J., Manders, W. A., Prins, P. J., \& van der Laan, P. (2012). Within-intervention change: Mediators of intervention effects during multisystemic therapy. Journal of Consulting and Clinical Psychology, 80(4), 574-587. https://doi.org/10.1037/a0028482 PMID:22563638

Coleman, P., \& Karraker, K. (2003). Maternal self-efficacy beliefs, competence in parenting, and toddlers' behavior and developmental status. Infant Mental Health Journal, 24(2), 126-148. https://doi.org/10.1002/imhj.10048

Kendall, S., \& Bloomfield, L. (2005). Developing and validating a tool to measure parenting self-efficacy. Journal of Advanced Nursing, 51(2), 174-181. https://doi.org/10.1111/ j.1365-2648.2005.03479.x PMID:15963189

Jones, T. L., \& Prinz, R. J. (2005). Potential roles of parental self-efficacy in parent and child adjustment: A review. Clinical Psychology Review, 25(3), 341-363. https://doi. org/10.1016/j.cpr.2004.12.004 PMID:15792853

Martins, C., \& Gaffan, E. A. (2000). Effects of early maternal depression on patterns of infant-mother attachment: A meta-analytic investigation. Journal of Child Psychiatry, 41(6), 737-746. https://doi.org/10.1111/1469-7610.00661 PMID:11039686

Marvin, R., Cooper, G., Hoffman, K., \& Powell, B. (2002). The Circle of Security project: Attachment-based intervention with caregiver-pre-school child dyads. Attachment \& Human Development, 4(1), 107-124. https://doi. org/10.1080/14616730252982491 PMID:12065033

Patel, V., Rodrigues, M., \& DeSouza, N. (2002). Gender, poverty, and postnatal depression: A study of mothers in Goa, India. Journal of Psychiatry, 159(1), 43-47. https://doi. org/10.1176/appi.ajp.159.1.43 PMID:11772688

Powell, B., Cooper, G., Hoffman, K., \& Marvin, R. (2009). The circle of Security. In C. Zeanah (Ed.), Handbook fo infant mental health (3rd ed., pp. 450-467). New York, NY: Guilford Press.

Teti, D. M., \& Gelfand, D. M. (1991). Behavioral competence among mothers of infants in the first year: The mediational role of maternal self-efficacy. Child Development, 62(5), 918-929. https://doi.org/10.2307/1131143 PMID:1756667

Whittaker, K. A., \& Cowley, S. (2006). Evaluating health visitor parenting support: Validating outcome measures for parental self-efficacy. Journal of Child Health Care, 10(4), 296-308. https://doi.org/10.1177/1367493506067882 PMID:17101622

Wittkowski, A., Dowling, H., \& Smith, D. M. (2016). Does Engaging in a Group-Based Intervention Increase Parental Self-efficacy in Parents of Preschool Children? A Systematic Review of the Current Literature. Journal of Child and Family Studies, 25(11), 3173-3191. https://doi.org/10.1007/ s10826-016-0464-z PMID:27795657 